\title{
Synthesis of Aqueous Dispersion of Graphenes via Reduction of Graphite Oxide in the Solution of Conductive Polymer
}

\author{
Sungkoo Lee, Kyeong K. Lee and Eunhee Lim \\ Korea Institute of Industrial Technology \\ Korea
}

\section{Introduction}

Graphene is a quasi-two-dimensional material. Two-dimensional conductor graphene has recently attracted attention due to in-plane mechanical, thermal, and electronic properties as well as its applications in future optoelectronic devices. These excellent properties may be relevant at the nanoscale if graphite can be exfoliated into thin nanoplatelets, and even down to the single graphene sheet level. Recently, the size of graphene films produced is limited to small sizes because the films are produced mostly by exfoliating graphite, which is not a scalable technique. Graphene sheets were produced by chemical reduction of exfoliated graphite oxides [1-5]. Hydrophilic graphite oxide was prepared by oxidation of pristine graphite [6,7] and it has functional groups such as epoxide, diol, ether, ketone, and hydroxyl groups. These functional groups in graphite oxide impart water solubility to the individual sheets. Solution processable graphite oxide has been used to fabricate paper like films with excellent mechanical properties, as well as electrically conductive polymeric composites [8]. But because of these functional groups, graphite oxide is electrically insulating. High conductivity graphene nanosheets were prepared via chemical reduction process of graphite oxide to graphite. But in the process of reduction, reduced graphite flakes agglomerate and eventually precipitate. This precipitated graphite flakes could not be re-dispersed by sonication in water containing surfactants. To avoid agglomeration of grapheme, other host polymers such as poly(4styrenesulfonic acid) must be used, which hamper the electron-transfer property of the graphenes [9,10].

The solution processing compatibility of graphenes make the material attractive for large area applications. But chemically reduced GO films showed low conductivities as high as 0.5 $\mathrm{S} / \mathrm{cm}$. However such level of conductivity is not sufficient for transparent electrode applications. So, we explore the direct preparation method of graphene solution by the reduction of graphite oxide in the solution ionic conductive polymer. As a result, we obtained a stable aqueous dispersion of graphene. The obtained graphene, coated with conductive polymer, can be re-dispersed in water. The structural and electrical properties of graphene were also examined with FT-IR, SEM, XPS, and 4-point probe conductivity method. 


\section{Experimental}

\subsection{Materials and methods}

Graphite oxide was synthesized from natural graphite, obtained from Sigma-Aldrich Company. Hydrazine hydrate was used for the reduction of graphite oxide. Deionized water was used as solvent. Poly(4-styrenesulfonic acid) (PSS) and Nafion were used as surfactants. These materials were obtained from Sigma-Aldrich Company. PEDOT:PSS(Baytron P), was purchased as an aqueous dispersion from H.C.Starck, Germany. The actual solid content in Baytron P is 1.5-2\% according to the manufacturer. All of the reagents were used as received without further treatment.

Fourier transform infrared (FT-IR) spectra were recorded in the range $400-4000 \mathrm{~cm}^{-1}$ with a $4 \mathrm{~cm}^{-1}$ resolution from $\mathrm{KBr}$ pellets on a Perkin-Elmer Spectrum. UV/Vis spectra of aqueous graphene dispersion were collected using a Shimadzu UV-2550 UV/Vis spectrophotometer. The chemical state and composition of the graphene thin films were examined by a Perkin Elmer XPS (model PHI 5500) apparatus at a base pressure in the vacuum chamber lower than $107 \mathrm{~Pa}$. The mixture of PEDOT/PSS and polymer-coated graphene was prepared by the solution of polymer-coated graphene adding into PEDOT/PPS solution and stirred for 1hr. The mixture was filtered with $0.45 \mu \mathrm{m}$ Teflon filter before being used for spin coating. The spin-coated film was dried at $120{ }^{\circ} \mathrm{C}$. Before spin coating, substrates were cleaned using TCE, water, and ethanol. The film thickness was determined using Alpha-step. The sheet resistance of films was measured by four-point probe method at room temperature.

\subsection{Preparation of water-soluble graphene oxide (GO)}

Graphene oxide was prepared using modified Hummers method from graphite [11]. The graphite was chemically oxidized by treatment with $\mathrm{NaNO}_{3}, \mathrm{KMnO}_{4}, \mathrm{H}_{2} \mathrm{SO}_{4}$, and $\mathrm{H}_{2} \mathrm{O}_{2}$, and washed with mixed aqueous solution of $3 \mathrm{wt} \% \mathrm{H}_{2} \mathrm{SO}_{4}$ and $0.5 \mathrm{wt} \% \mathrm{H}_{2} \mathrm{O}_{2}$.

Impurities were removed by centrifugation. The final resultant water solution was passed through a weak basic ion-exchange resin to remove the remaining $\mathrm{HCl}$ acid. Then water was removed through a drying process. Finally, the brown powder was obtained.

\subsection{Chemical reduction of graphite oxide}

GO (100 mg) was dispersed in $100 \mathrm{ml}$ of water. This dispersion was sonicated until it became clear with no visible particulate matter. Hydrazine hydrate was added and the solution was heated in an oil bath at $100{ }^{\circ} \mathrm{C}$ for $24 \mathrm{~h}$. Reduced GO gradually precipitated out as a black solid. This product was isolated by filtration and washing copiously with water. The obtained reduced graphite oxide powder was dried on the vacuum oven at $150{ }^{\circ} \mathrm{C}$ for $24 \mathrm{~h}$. This material could not be re-suspended even after prolonged ultrasonic treatment in water.

\subsection{Nafion-coated graphite sheets via reduction of graphite oxide}

GO (100 mg) was dispersed in $100 \mathrm{ml}$ of water and the resulting suspension was sonicated for $1 \mathrm{~h}$. After adding Nafion to the aforesaid suspension and stirring for $4 \mathrm{~h}$, hydrazine hydrate was added to the above mixture. The mixture was continuously stirred at $100{ }^{\circ} \mathrm{C}$ for $24 \mathrm{~h}$. As the reduction proceeds, color of polymer-coated graphite oxide change from brown to black. The polymer-coated graphene was isolated via filtration with PVDF membrane ( $0.45 \mu \mathrm{m}$ pore size) and washed with water. Nafion-coated graphene can be re-dispersed in water upon sonication, forming black suspensions. 


\subsection{PSS-coated graphite sheets via reduction of graphite oxide}

GO (100 mg) was dispersed in $100 \mathrm{ml}$ of water and the resulting suspension was sonicated for $1 \mathrm{~h}$. After adding poly(4-styrenesulfonic acid) to the aforesaid suspension and stirring for $4 \mathrm{~h}$, hydrazine hydrate was added to the above mixture. The mixture was continuously stirred at $100{ }^{\circ} \mathrm{C}$ for $24 \mathrm{~h}$. As the reduction proceeds, color of polymer-coated graphite oxide change from brown to black. The polymer-coated graphene was isolated via filtration with PVDF membrane $(0.45 \mu \mathrm{m}$ pore size) and washed with water. PSS-coated graphene can be re-dispersed in water upon sonication, forming black suspensions.

\section{Results and discussion}

The graphite oxide is electrically insulating. The conductivity of graphene can be obtained by removal of the oxidized moieties in the graphite oxide by chemical reduction. But in the process of reduction, reduced graphite flakes agglomerate and eventually precipitate. We prepared the stable aqueous dispersions of graphite nanoplatelets by chemical reduction in the aqueous polymer, Nafion or PSS. Figure 1 shows pictures of the water dispersion of reduced graphite and PSS- and Nafion-coated graphene. Reduced graphite was not dispersed in water but PSS-coated graphene (RGO-PSS) and Nafion-coated graphene (RGONafion) were dispersed readily in water. During reduction, Nafion (or PSS) interact with platelets to compete with hydrophobic interaction between the graphite platelets. But once Nafion (or PSS) is attached to the graphite platelet surface, agglomeration of the graphite platelet is stopped [9].

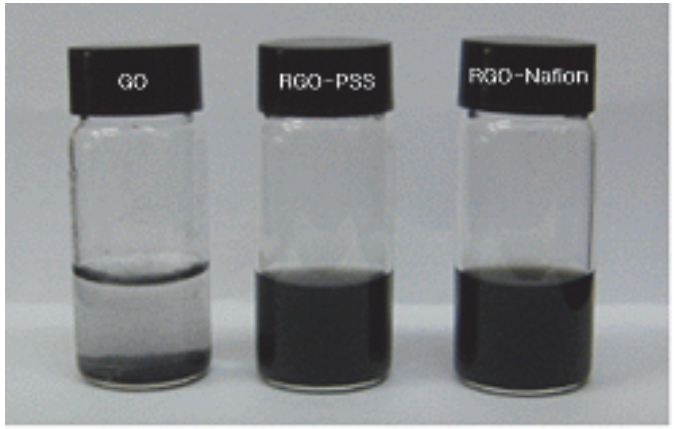

Fig. 1. Water dispersions of reduced graphite oxide (a), reduced graphite oxide with PSS (b) and Nafion (c)

Figure 2 shows the FT-IR spectra of GO before reduction, and after reduction without and with PSS or Nafion. In figure 2a, a FT-IR spectrum of GO shows a broad absorption band at $3390 \mathrm{~cm}^{-1}$, which is related to the $\mathrm{OH}$ groups, and absorption bands at $1629 \mathrm{~cm}^{-1}$ and $1720 \mathrm{~cm}^{-1}$, which are typical of carbonyl and carboxyl groups. Figure $2 \mathrm{c}$ and $2 \mathrm{~d}$ show the characteristic bands, corresponding to PSS and Nafion.

In figure 2, we know that there are considerable changes in FT-IR spectra of GO after treatment with hydrazine hydrate. The hydrazine hydrate treatment eliminated all of GO bands, giving evidence for the almost removal of the oxygen-containing groups (figure $2 b$, $2 \mathrm{c}, 2 \mathrm{~d}$ ). As a result of this, the graphene was prepared by chemical reduction in aqueous polymer solution, PSS or Nafion. 


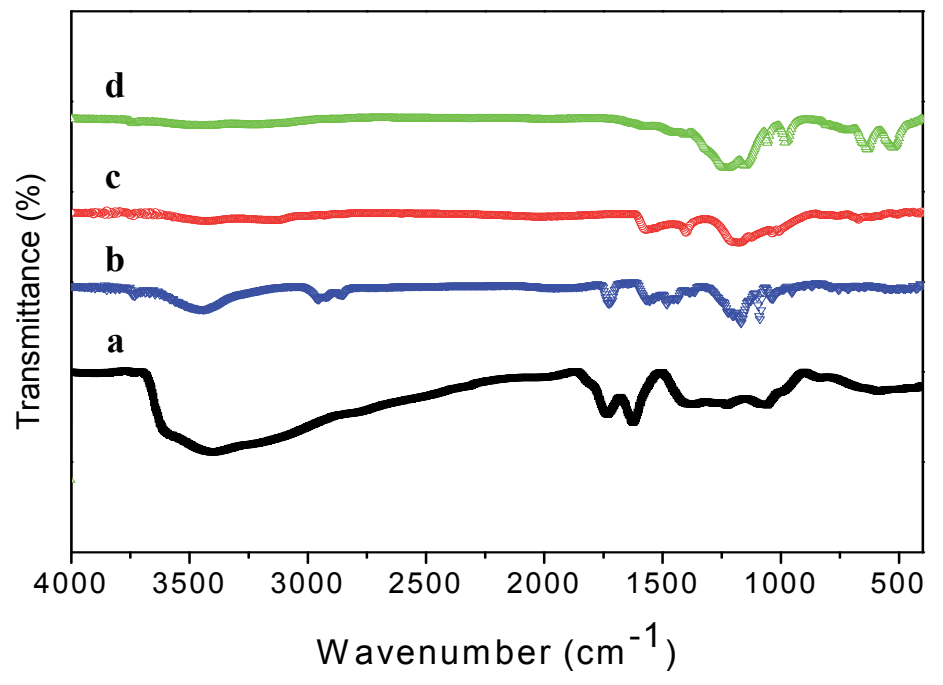

Fig. 2. FT-IR spectra in KBr of the samples GO (a), RGO (b), RGO-PSS (c), RGO-Nafion (d)

Figure 3 shows the UV/Vis spectra of polymer-coated RGO in water. RGO-PSS has two absorption peaks in the UV/Vis spectrum. The absorption at $230 \mathrm{~nm}$ ascribed to the PSS and that at $280 \mathrm{~nm}$ to reduced graphite oxide. It is known that the peak at $280 \mathrm{~nm}$ is the characteristic peak of graphite in solution. The intensities of the signal of the polymers (PSS and Nafion) are also small, indicating the polymer is strongly attached to the graphene surface [8]. In figure 3(b), Nafion-coated graphene show only the peak of the RGO. Due to the higher absorbance of RGO, Nafion peak may be getting masked in the spectrum, because there is not the absorption peak in UV/Vis spectrum of nafion. In figure 3, RGO-PSS and RGO-Nafion have all the characteristic peak of RGO. This shows that polymer-coated graphene have the stable state in the water solution. The chemical composition of both PSS- and Nafion-coated graphene was monitored by X-Ray photoelectron spectroscopy (XPS). Figure 4 shows XPS analysis of graphite oxide and polymer-coated graphenes. The C 1s XPS spectrum of GO indicates a considerable degree of oxidation with four major signatures corresponding to carbon atoms in different functional groups. They are non-oxygenated ring $\mathrm{C}$ at $284.8 \mathrm{eV}, \mathrm{C}$ of $\mathrm{C}-\mathrm{O}$ bonds at $286.1 \mathrm{eV}, \mathrm{C}$ of $\mathrm{C}=\mathrm{O}$ at $287.3 \mathrm{eV}$, and that of carboxylate carbon $(\mathrm{O}-\mathrm{C}=\mathrm{O})$ at $289.0 \mathrm{eV}$ [12]. Oxygen functionalities of the graphite oxide were decreased during the reduction progressed. C 1s XPS of RGO-PSS and RGO-Nafion also showed similar to spectra of GO. However the intensities of oxygenated carbon peaks are considerably decreased, implying reduction. In addition, there is an additional component at $285.8 \mathrm{eV}$ corresponding to $\mathrm{C}$ bound to nitrogen of hydrazones. The C 1s XPS spectrum of the Nafion-coated reduced graphite oxide sample also contains a component peak at $292.7 \mathrm{eV}$ corresponding to the fluorine-bonded carbon atoms from Nafion. 

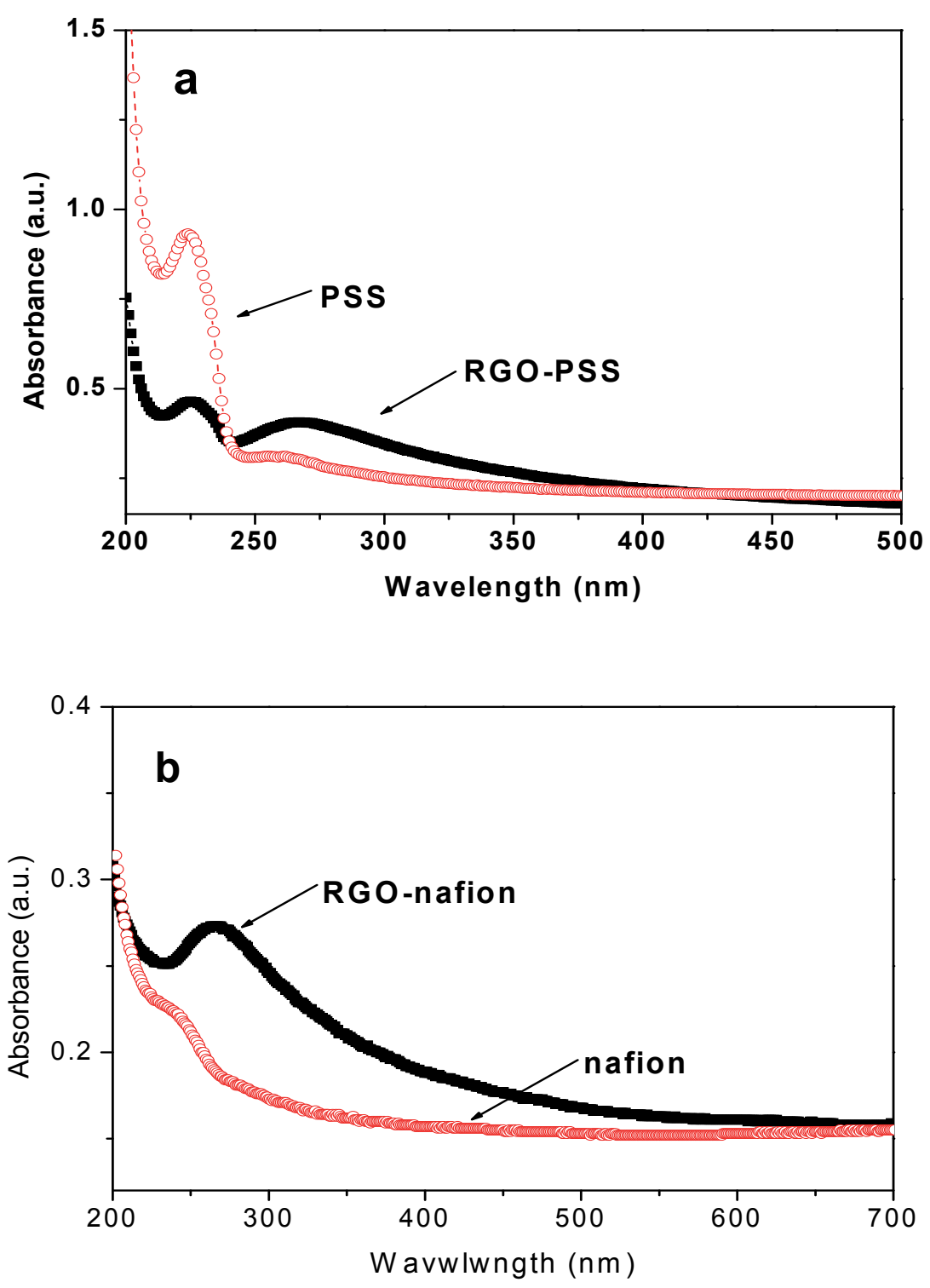

Fig. 3. UV-Vis spectra of the polymer-coated graphene. PSS-RGO (a), Nafion-RGO (b). 

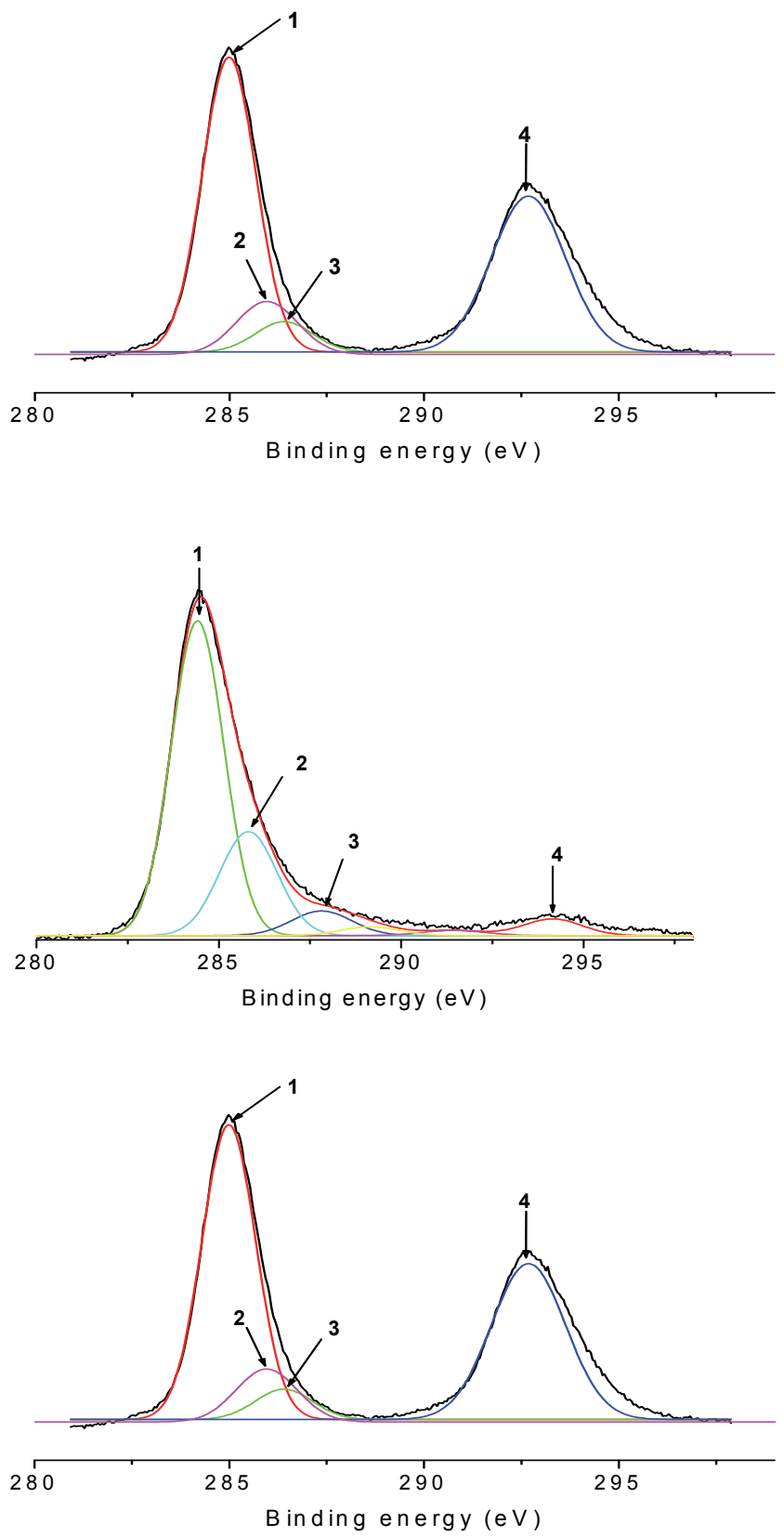

Fig. 4. XPS analysis of graphite oxide (a), PSS-coated graphene (b), Nafion-coated graphene (c). 
The conductivities of PEDOT films as a function of the graphene content were shown in figure 5 . The thickness of the films range $0.1 \mu \mathrm{m}$ to $0.3 \mu \mathrm{m}$. As the polymer-coated graphene content in PEDOT/PSS solution increase from 0 to $1.2 \mathrm{wt} \%$, the conductivity of graphenedoped PEDOT film increases. The PEDOT/PSS film with RGO-Nafion increased significantly from $0.25 \mathrm{~S} / \mathrm{cm}$ for pure PEDOT film and reached $12 \mathrm{~S} / \mathrm{cm}$, and the film with RGO-PSS showed $3.2 \mathrm{~S} / \mathrm{cm}$ when graphene was doped to $1.2 \times 10-3 w t \%$ in PEOT solution. The conductivity of PEDOT doped Nafion-coated graphene were increased approximately 60 -fold than the origin PEDOT film. This indicates that the doped graphene strongly influences the conductivity of PEDOT film. The film of PEDOT doped with RGO-Nafion had also higher conductivities than films doped with RGO-PSS. It is known that Nafion has ionic conductive property and PSS is the insulating material. As a result, it implies that the graphene coated with ionic conductive material contributes to enhancement of conductivity than that coated insulating material.

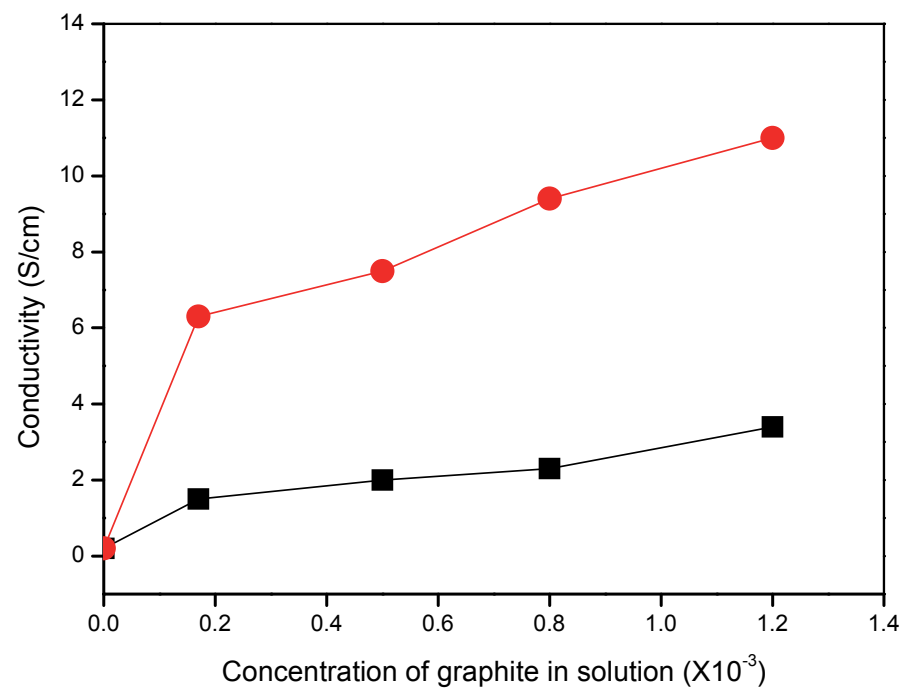

Fig. 5. Conductivity of PEDOT films with varying doping content

\section{Conclusion}

In this study, we carried to the reduction of graphite oxide in the soluble Nafion, ionic conductive polymer. Reduced graphite was not dispersed in water but polymer-coated graphenes (RGO-PSS and RGO-Nafion) were dispersed readily in water, and readily forms stable dispersed state. There are considerable changes in FT-IR spectra of GO after treatment with hydrazine hydrate, implying successful reduction of graphite oxide in aqueous solution of Nafion. UV/Vis spectrum of RGO-Nafion is similar to the characteristic peak of RGO. It indicated that Nafion-coated graphene have the stable state in the water solution. 
The PEDOT film with Nafion-coated graphene increased significantly from $0.25 \mathrm{~S} / \mathrm{cm}$ for pure PEDOT film and reached $12 \mathrm{~S} / \mathrm{cm}$. The film of PEDOT doped Nafion-coated graphene had also higher conductivities than films doped PSS-coated graphene.

\section{References}

Hong, W.; Xu Y.; Lu G.; Li C.\& Shi G. (2008) Electrochemistry Comm., Vol.10, pp. 1555-1558, ISSN 1388-2481

Novoselov, K.S.; Geim, A.K.; Morozov, S.V.; Jiang, D.; Zheng, Y.; Dubonos, S.V; Grigorieva, I.V. \& Firsov A.A. (2004) Science, Vol.306 pp. 666, ISSN 0036-8075

Li, D.M. ; Muller, M.B. ; Gilje, S. ; Kanner, R.B. \& Wallace, G.G. (2008) Nat. Nanotechnol. Vol.3 pp. 101-105, ISSN 1748-3387

Stankovich, S. ; Piner, R.D. ; Nfuyen, S.T. \& Ruoff, R.S. (2006) Carbon, Vol.44 pp. 3342-3347, ISSN 0008-6223

Brodie, B.C. (1960) Ann. Chim. Phys., Vol.59 pp. 466-472

Hua, L. ; Kai, W. \& Inoue, Y. (2007) J. Appl. Polym. Sci., Vol.106 pp. 1880-1884, ISSN 10974628

Becerril, H.A. ; Mao, J. ; Liu, Z. ; Stoltenberg, R.M. ; Bao, Z. \& Chen, Y. (2008) ACS Nano, Vol.2 pp. 463-470, ISSN 1936-0851

Stankovich, S. ; Piner, R.D. ; Chen, X. ; Wu, N. ; Nguyen, S.T. \& Ruoff, R.S. (2006) J. Matter. Chem., Vol.16 pp. 155-158, ISSN 0959-9428

Chen, G.; Weng, W.; Wu, D. \& Wu, C. (2003) European Polymer Journal, Vol.39 pp. 2329-2335, ISSN 0014-3057

Hummers, W.S. \& Offeman, R.E. (1958) J. Am. Chem. Soc., Vol.80 pp. 1339, ISSN 0002-7863

Stankovich, S. ; Dikin, D.A. ; Piner, R.D. ; Kohlhaas, K.A. ; Kleinhammes, A. ; Jia, Y. ; Wu, Y. ; Nguyen, S.T. \& Ruoff, R.S. (2007) Carbon, Vol.45 pp. 1558-156, ISSN 0008-6223 


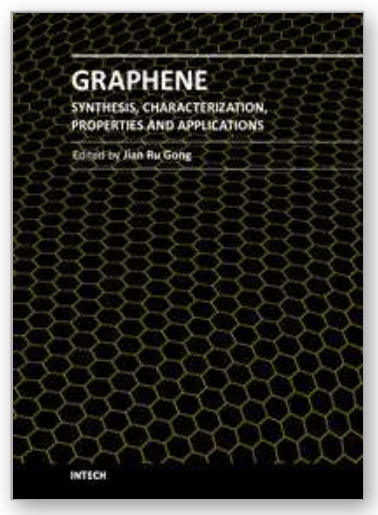

\author{
Graphene - Synthesis, Characterization, Properties and \\ Applications \\ Edited by Prof. Jian Gong
}

ISBN 978-953-307-292-0

Hard cover, 184 pages

Publisher InTech

Published online 15, September, 2011

Published in print edition September, 2011

The discovery of graphene has led to a deluge of international research interest, and this new material in the field of materials science and condensed-matter physics has revealed a cornucopia of new physics and potential applications. This collection gives a roughly review on the recent progress on the synthesis, characterization, properties and applications of graphene, providing useful information for researchers interested in this area.

\title{
How to reference
}

In order to correctly reference this scholarly work, feel free to copy and paste the following:

Sungkoo Lee, Kyeong K. Lee and Eunhee Lim (2011). Synthesis of Aqueous Dispersion of Graphenes via Reduction of Graphite Oxide in the Solution of Conductive Polymer, Graphene - Synthesis, Characterization, Properties and Applications, Prof. Jian Gong (Ed.), ISBN: 978-953-307-292-0, InTech, Available from: http://www.intechopen.com/books/graphene-synthesis-characterization-properties-and-applications/synthesisof-aqueous-dispersion-of-graphenes-via-reduction-of-graphite-oxide-in-the-solution-of-cond

\section{INTECH}

open science | open minds

\section{InTech Europe}

University Campus STeP Ri

Slavka Krautzeka 83/A

51000 Rijeka, Croatia

Phone: +385 (51) 770447

Fax: +385 (51) 686166

www.intechopen.com

\section{InTech China}

Unit 405, Office Block, Hotel Equatorial Shanghai

No.65, Yan An Road (West), Shanghai, 200040, China

中国上海市延安西路 65 号上海国际贵都大饭店办公楼 405 单元

Phone: +86-21-62489820

Fax: +86-21-62489821 
(C) 2011 The Author(s). Licensee IntechOpen. This chapter is distributed under the terms of the Creative Commons Attribution-NonCommercialShareAlike-3.0 License, which permits use, distribution and reproduction for non-commercial purposes, provided the original is properly cited and derivative works building on this content are distributed under the same license. 